\title{
Growth Inhibition of Soil Fungi by Insecticides and Annulment of Inhibition by Yeast Extract or Nitrogenous Nutrients
}

\author{
By G. T. COWLEY* AND E. P. LICHTENSTEIN \\ Department of Entomology, University of Wisconsin, \\ Madison, Wisconsin 53706, U.S.A.
}

(Accepted for publication 5 March 1970)

\begin{abstract}
SUMMARY
Seventeen fungal species from Wisconsin prairie soils were grown on Czapek nutrient media that had been treated with the insecticides aldrin, lindane, parathion, phorate or carbaryl. All five insecticides inhibited to some extent the growth of most fungal species; this inhibition was a result of a particular insecticide-fungus combination. Threshold concentrations of insecticides, at which no decrease in growth of Aspergillus fumigatus or Fusarium oxysporum occurred, differed for each insecticide and also for each of the two fungi. Since most of the insecticides had some fungicidal effect, it was not surprising that none of the 17 fungi was able to utilize any of the insecticides as a carbon or phosphorus source. Carbaryl or aldrin at $20 \mu \mathrm{g} . / \mathrm{ml}$. inhibited growth of $F$. oxysporum by 37 to $44 \%$. However, the addition of yeast extract, asparagine, ammonium sulphate, ammonium nitrate or ammonium sulphamate to the culture media resulted in a complete suppression of the growth inhibitory effect of carbaryl and that of aldrin to a large extent. Replacement of yeast extract with a vitamin mixture had no effect; fungal growth was still inhibited.
\end{abstract}

\section{INTRODUCTION}

The use of agricultural chemicals over the last 25 years has presented problems pertaining to the interaction of residual pesticides of long persistence with biological systems in the environment. A considerable amount of pesticides, even if not applied directly to soils, ultimately ends in the upper soil layers. Hence the interaction of pesticides with soil micro-organisms has drawn considerable attention from many workers (Engst \& Kujawa, I968; Matsumura, Boush \& Tai, I968; Kearney, Kaufman, von Endt \& Guardia, I969; Sethunathan \& MacRae, 1969). Many of these studies dealt with the problem of reducing the concentration of insecticidal residues in soils. Efforts were made to isolate species of micro-organisms that would be able to degrade and to detoxify pesticidal residues, especially those of a more persistent nature; also the effects of pesticidal residues on micro-organisms in soil are of importance (Ko \& Lockwood, 1968). Richardson \& Miller ( 1960) tested the toxic effects of eight chlorinated hydrocarbon insecticides on mycelial growth of some fungi; they concluded that the water solubility and vapour pressure of a particular insecticide were major factors responsible for the degree of toxicity to fungi as determined by the diameter of

* Presentaddress: Department of Biology, University of South Carolina, Columbia, South Carolina, U.S.A. 
mycelia produced. In the present study an attempt has been made to investigate the toxic effects of some chlorinated hydrocarbon, organophosphorus and carbamate insecticides on soil fungi as affected by nutritional factors.

\section{METHODS}

Organisms. Fungi used in this study were isolated by Orpurt \& Curtis (1957) from the upper inch layer of Wisconsin prairie soils, which had not been disturbed by grazing or ploughing. Because of their similarities to Wisconsin agricultural soils, prairie soils were chosen as the source of the fungal species. Seventeen fungi were selected on account of their high frequency in these soils; nine of these fungal species belonged to the genus Penicillium.

Culture media. The basal culture medium used was a modified Czapek nutrient agar (Ainsworth, I960) in which glucose was the carbon source.

The insecticides used were two chlorinated hydrocarbon compounds (aldrin, lindane), two organophosphorus compounds (parathion and phorate) and one carbamate (carbaryl or Sevin $\left.{ }^{\circledR}\right)$. They were all of analytical grade. Ethanol $(95 \%, \mathrm{v} / \mathrm{v}$ in water) was used as solvent for the insecticides.

Yeast extract, thiamine, riboflavin, pyridoxine, niacin, pantothenic acid, biotin, inositol, choline, folic acid and vitamin $B_{12}$ were added to some culture media to test the potential interaction of insecticides with various growth-promoting substances. The effects of asparagine, ammonium sulphate, ammonium nitrate and ammonium sulphamate were also investigated.

Treatment and inoculation of culture media. Culture media were sterilized by autoclaving for $20 \mathrm{~min}$. at $12.0 \mathrm{lb}$. pressure. After the media had cooled to 45 to $50^{\circ}$ and while still liquid they were treated with different ethanolic solutions of the insecticides. The concentration of ethanol never exceeded $0.2 \%(\mathrm{v} / \mathrm{v})$ in the medium. Culture media that had been treated only with ethanol served as controls. The various growth substances of nitrogenous materials were added in aqueous solution before sterilization of the culture media.

About $20 \mathrm{ml}$. of each medium were poured into each of 4 Petri dishes, to give 4 replicates. Plates were inoculated by transferring a small agar block containing hyphal tips from a standard culture of one of the fungi which previously had been grown on the basal culture medium. Plates were then incubated as described for each experiment.

Evaluation of insecticidal effects. At the end of the incubation period relative sporulation was evaluated by visual inspection, and the diameter of each fungus colony was recorded. The colonies were harvested for dry weight determinations by melting the agar at $100^{\circ}$ and transferring to a boiling water bath. The colonies were then washed for $2 \mathrm{~min}$. in three successive baths to remove agar adhering to the mycelia. Each mycelial mat was then placed on an oven-dried and tared filter paper in a Buchner funnel and washed with warm water. The washed colonies and the filter paper were dried overnight at 80 to $90^{\circ}$ before the final weight determinations. It was felt that determination of the dry weight was the most reliable criterion for measuring insecticide toxicity. All data were analysed with the t-test.

Basically, the following four experiments were conducted.

Experiment 1 . Effects of insecticides on growth of soil microfungi. This experiment was done as an initial screening test for establishing toxic effects and the selection of 
specific fungi for future investigations. Basal culture media were treated at the relatively high dosage of $40 \mathrm{ug} . / \mathrm{ml}$. with either aldrin, lindane, parathion, phorate or carbaryl. These media were then inoculated, giving 85 combinations of 5 insecticides and 17 fungi. Depending on the growth rate of each species the fungi were incubated at $25 \pm \mathrm{I}^{\circ}$ for 7 to $\mathrm{I} 2$ days. Relative amounts of sporulation were then determined and growth measurements (diameter, weight) were made.

Experiment 2. Threshold concentrations of insecticides affecting growth of two microfungi. Tests were made to determine the highest insecticide concentration (threshold concentration) at which no significant ( $\%$ level, t-test) decrease of fungal growth occurred. For this Aspergillus fumigatus and Fusarium oxysporum were exposed to increasing concentrations ( $\mathrm{I}, 2,5, \mathrm{IO}, 20,40 \mu \mathrm{g} . / \mathrm{ml}$.) of each of the five insecticides. These fungi were selected because of their relatively rapid growth rate and their susceptibility to all five insecticides. After inoculation of the culture media, these were incubated for 5 days at $34 \pm 3^{\circ}$. The dry weight of each fungus colony was then determined.

Experiment 3. Effects of insecticides on fungi, grown on media lacking glucose or inorganic phosphate. Culture media were prepared that lacked glucose or inorganic phosphate $\left(\mathrm{K}_{2} \mathrm{HPO}_{4}\right)$. The glucose-deficient media were treated with one of the five insecticides at $40 \mu \mathrm{g} . / \mathrm{ml}$. while the potassium phosphate-deficient media were treated with parathion or phorate at $40 \mu \mathrm{g}$. $/ \mathrm{ml}$. Media deficient in glucose or inorganic phosphate, but treated with ethanol only, served as controls. Results (growth and sporulation measurements) were then compared with data obtained after fungi had also grown on complete media, previously treated with either ethanol or with an insecticide in ethanol.

Experiment 4. Counteraction of insecticidal effects. (a) With yeast extract. An experiment identical to the tests for the determination of threshold concentrations (Expt. 2) was made, except that $0.15 \%(\mathrm{w} / \mathrm{v})$ yeast extract ('Difco') was added to the culture media. This was done to determine whether the presence of yeast extract counteracted inhibitory effects of the insecticides on the growth of Aspergillus fumigatus and Fusarium oxysporum. Production of fungal dry weight was used as a criterion for the evaluation of the effects of yeast extract and insecticides. Culture media + yeast extract but no insecticide served as controls; results were also compared with those obtained in the absence of yeast extract (Expt. 2).

(b) With vitamins. Experiments were also made with components of yeast extract (e.g. vitamins) with Fusarium oxysporum as test organism. This fungus, a very characteristic species of prairie soils, was selected because of its general sensitivity to the insecticides. It was grown on aldrin or carbaryl-treated $(20 \mu \mathrm{g} . / \mathrm{ml}$.) culture media to which yeast extract (control) or vitamins had been added.

Vitamins were used to determine whether the action of insecticides in decreasing the growth rate of the fungus was related to the function of certain vitamins within the mycelium. Aqueous solutions of the vitamins were prepared to give (per 1.) $2 \mathrm{mg}$. thiamine, $10 \mathrm{mg}$. riboflavin, $5 \mathrm{mg}$. pyridoxine, $30 \mathrm{mg}$. niacin, $30 \mathrm{mg}$. pantothenic acid, I mg. biotin, $0.75 \mathrm{~g}$. inositol, $0.75 \mathrm{~g}$. choline, I mg. folic acid and $\mathrm{I} 5 \mathrm{mg}$. vitamin $\mathrm{B}_{12}$. One $\mathrm{ml}$. of this solution was added to $100 \mathrm{ml}$. of basic medium, from which four agar plates were poured. The concentration of these vitamins was slightly higher than the amounts that would be present in yeast extract at a concentration of $0.15 \%(\mathrm{w} / \mathrm{v})$.

(c) With various nitrogenous compounds. Since the nature of the nitrogen source 
in the culture media might also be a factor that influences the degree of growth inhibition by insecticides, four nitrogen-containing compounds were used in addition to the $\mathrm{NaNO}_{3}$ which was a component of the basal culture medium. For this purpose, media were prepared to which asparagine, $\left(\mathrm{NH}_{4}\right)_{2} \mathrm{SO}_{4}, \mathrm{NH}_{4} \mathrm{NO}_{3}$ or $\mathrm{NH}_{4} \mathrm{SO}_{3} \mathrm{NH}_{2}$ were added to $0 . \mathrm{I} 5 \%(\mathrm{w} / \mathrm{v})$. These four different media were then treated with aldrin or carbaryl at $20 \mu \mathrm{g} . / \mathrm{ml}$., followed by inoculation. Colonies of the fungi were incubated and handled as described in Expt. 2.

\section{RESULTS AND DISCUSSION}

Experiment I. Effects of insecticides on growth of soil microfungi. Results on the effect of aldrin, lindane, parathion, phorate or carbaryl on growth and sporulation of I 7 soil microfungi are summarized in Table $\mathrm{I}$. They are expressed as the dry weight of each fungus from insecticide-treated media as a percentage of the dry weight that was produced in the absence of insecticides. All five insecticides inhibited to some extent the growth of most fungal species although various degrees of growth inhibition could be noticed.

Table I. Effect of five insecticides (at $40 \mu \mathrm{g} . / \mathrm{ml}$. in basic culture medium) on the growth and sporulation of various soil microfungi

Dry Weight as $\%$ of Control (culture medium $+0 \cdot 2 \%$ ethanol)

\begin{tabular}{|c|c|c|c|c|c|}
\hline Fungus & Aldrin & Lindane & Parathion & Phorate & Carbaryl \\
\hline Acrostalagmus sp. & $97 \pm 10 \cdot 7^{a}$ & $109 \pm 13 \cdot 3$ & $94 \pm 10 \cdot 2$ & $89 \pm 3 \cdot 1^{c}$ & $79 \pm 7 \cdot 0^{b}$ \\
\hline Aspergillus fumigatus & $76 \pm 4 \cdot 2^{b}$ & $75 \pm 10 \cdot 3^{c}$ & $58 \pm 2 \cdot 7^{b}$ & $62 \pm 16 \cdot 3^{b}$ & $52 \pm 10 \cdot 6^{b}$ \\
\hline A. terreus & $99 \pm 8 \cdot 6$ & $29 \pm 5 \cdot 7^{b a}$ & $52 \pm 9 \cdot 0^{b}$ & $57 \pm 3 \cdot 0^{b d}$ & $35 \pm 3 \cdot 8^{b}$ \\
\hline Emericellopsis sp. & $45 \pm 15 \cdot 4^{b}$ & $66 \pm 4 \cdot 6^{c}$ & $14 \pm 1 \cdot 0^{b}$ & $100 \pm 1 \cdot 0$ & $25 \pm 2 \cdot 7^{b}$ \\
\hline Fusarium oxysporum & $45 \pm 4 \cdot 7^{b}$ & $34 \pm 6 \cdot 9^{b}$ & $18 \pm 3 \cdot 5^{b}$ & $14 \pm 2 \cdot 2^{b}$ & $27 \pm 3 \cdot 6^{b}$ \\
\hline \multicolumn{6}{|c|}{ Myrothecium strigtosporum } \\
\hline & $100 \pm 14 \cdot 3$ & $12 \pm 1 \cdot 0^{b}$ & $20 \pm 3 \cdot 2^{b}$ & $42 \pm 3 \cdot 7^{b}$ & $32 \pm 4 \cdot 8^{b}$ \\
\hline Thielaviopsis sulphurellum & $82 \pm 4 \cdot 0$ & $49 \pm 2 \cdot 6^{b}$ & $19 \pm 1 \cdot 4^{b}$ & $99 \pm 2 \cdot 5$ & $27 \pm 3 \cdot 1^{b}$ \\
\hline Penicillium janthinellum & $78 \pm 5 \cdot 4^{b e}$ & $45 \pm 4 \cdot 5^{b d}$ & $3^{8} \pm 3 \cdot 2^{b}$ & $92 \pm 3 \cdot 0^{c}$ & $43 \pm 3 \cdot 9^{b}$ \\
\hline P. javanicum & $70 \pm 4 \cdot 8^{b}$ & $77 \pm \mathrm{II} \cdot 8^{c}$ & $55 \pm 3 \cdot 0^{b}$ & & \\
\hline P. lilacinum & $96 \pm I \cdot 8$ & $56 \pm 8 \cdot I^{b}$ & $60 \pm 5 \cdot 9^{b}$ & $65 \pm 3 \cdot 2^{b}$ & $44 \pm 3 \cdot 5^{b}$ \\
\hline P. nigricans & $89 \pm 5.8^{e}$ & $40 \pm 3 \cdot 3^{b d}$ & $62 \pm 2 \cdot 2^{b d}$ & $87 \pm \mathrm{I} \cdot 8^{b d}$ & $58 \pm 3 \cdot 5^{b d}$ \\
\hline$P$. restrictum & $84 \pm 5^{\circ} 0^{c}$ & $67 \pm \mathrm{I} \cdot \mathrm{I}^{b}$ & $55 \pm 3 \cdot 2^{b}$ & $102 \pm 4 \cdot 5$ & $72 \pm 6 \cdot 5^{b}$ \\
\hline$P$. roseo-purpureum & $87 \pm 7 \cdot 4^{d}$ & $34 \pm 5 \cdot 3^{b d}$ & $34 \pm 2 \cdot 6^{b}$ & $94 \pm 2 \cdot 4^{c}$ & $61 \pm 3 \cdot 1^{b}$ \\
\hline P. simplicissimum & $83 \pm 2 \cdot 2^{c e}$ & $92 \pm 9 \cdot 2$ & $69 \pm 3 \cdot 9^{b d}$ & $62 \pm 2 \cdot 8^{b}$ & $77 \pm 4 \cdot 1^{b}$ \\
\hline P. thomii & $102 \pm 2 \cdot 5^{d}$ & $66 \pm 6 \cdot 8^{b a}$ & $52 \pm 4 \cdot 7^{b e}$ & $40 \pm \mathrm{I} \cdot 8^{b e}$ & $6 \pm 0 \cdot 3^{b d}$ \\
\hline P. variabile & $93 \pm 4 \cdot 9$ & $49 \pm 2 \cdot 7^{b}$ & $6 \mathrm{I} \pm 3 \cdot 2^{b e}$ & $87 \pm 4 \cdot 1^{b d}$ & $5 \mathrm{I} \pm 5 \cdot 4^{b}$ \\
\hline Paecilomyces marquandii & $101 \pm 3 \cdot 7^{c}$ & $26 \pm 3 \cdot 2^{b}$ & $39 \pm 4 \cdot 3^{b e}$ & $86 \pm 2 \cdot 1^{b d}$ & $98 \pm 3 \cdot 9$ \\
\hline
\end{tabular}

Based on the number of species inhibited, aldrin was the least toxic since the growth of only 7 out of 17 species was significantly affected. Lindane inhibited the growth of 15 fungi, parathion of 16 , phorate of 13 and carbaryl of 15 species. Based on the $\%$ decrease in dry weight, aldrin and phorate were least toxic, since the growth of only 2 and 3 fungi respectively was inhibited by more than $50 \%$. Lindane, parathion and carbaryl, however, caused a growth inhibition of more than $50 \%$ with 7 to 9 fungal species. Since there was no species which was affected to the same degree by all insecticides and since there was no insecticide that affected all fungi in the same manner, the observed data are results of particular insecticide-fungus combinations. 
Experiment 2. Threshold concentrations of insecticides affecting growth of two microfungi. After Aspergillus fumigatus and Fusarium oxysporum had been exposed to the insecticides, the dry weight of each mycelial mat was expressed as $\%$ dry weight of fungi grown on control media (ethanol-treated). Figure I summarizes the results obtained. Two conclusions can be drawn: (i) the highest concentration of the chemicals (Fig. I T) at which no significant (at the I \% level) decrease of fungal growth occurred differed for each insecticide; (ii) this threshold concentration was also a function of

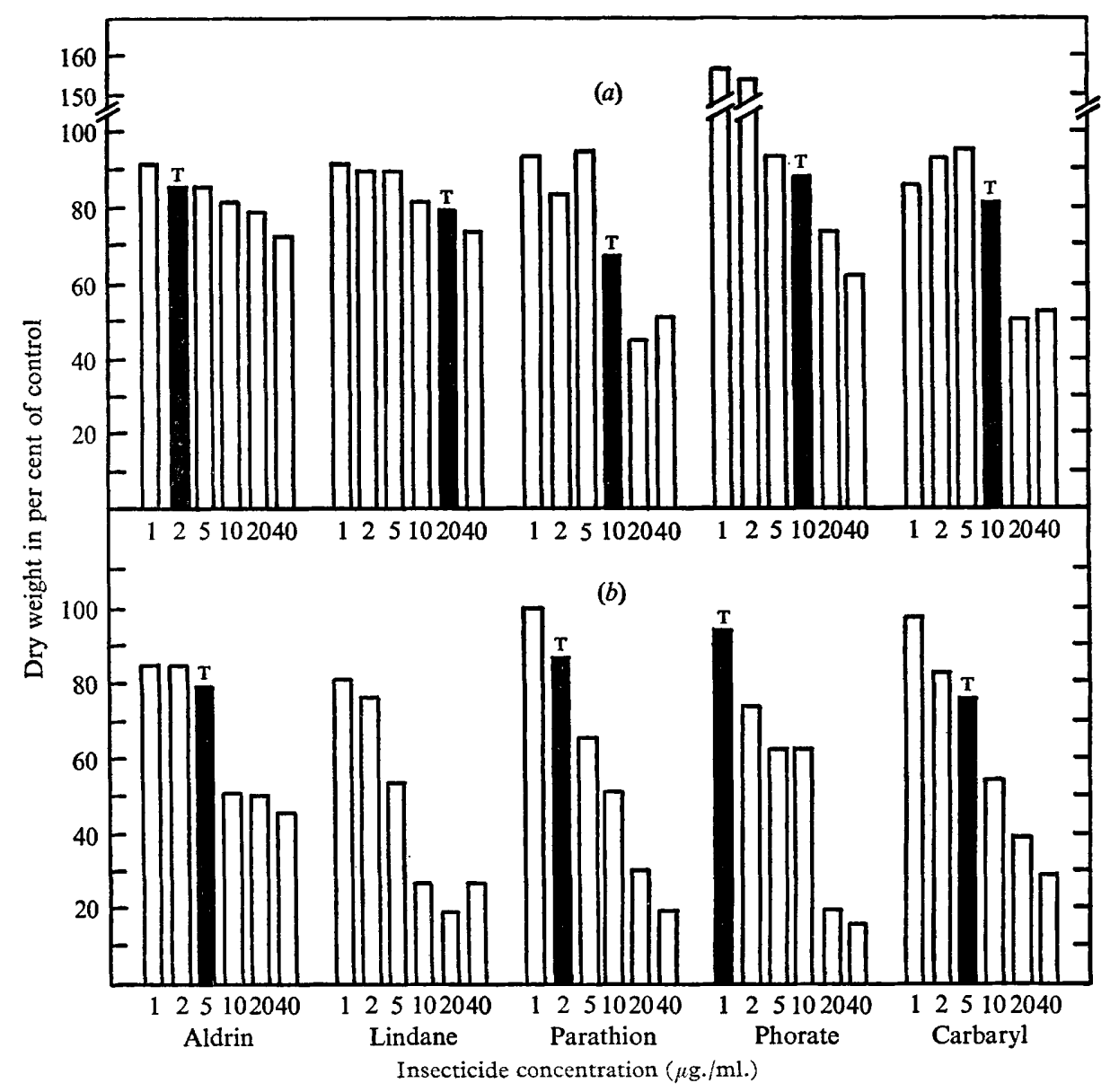

Fig. I. Effects of five insecticides on the growth of Aspergillus fumigatus (a) and Fusarium oxysporum $(b) . \mathrm{T}=$ Highest insecticide concentration (threshold) at which no significant ( $1 \%$ level) decrease of fungal growth occurred.

the test organism, and was different for each of the two fungi. In general, growth of A. fumigatus (Fig. I $a$ ) was less affected by the insecticides than was the growth of F. oxysporum (Fig. I b). Aspergillus fumigatus was, however, very susceptible to aldrin, which at both 2 and $5 \mu \mathrm{g} . / \mathrm{ml}$. caused a $14 \%$ decrease of fungal growth. Because the variation between replicates was relatively large at $2 \mu \mathrm{g} . / \mathrm{ml}$., this 'inhibition' was not significantly different from the control. The concentration of $2 \mu \mathrm{g}$. $/ \mathrm{ml}$. of aldrin was 
therefore regarded as the threshold that did not inhibit fungal growth. Phorate at I and $2 \mu \mathrm{g} . / \mathrm{ml}$. caused a significant (I \% level) growth stimulation of $A$. fumigatus while its threshold concentration was $10 \mu \mathrm{g}$. $/ \mathrm{ml}$. With $F$. oxysporum, lindane inhibited its growth even at a concentration of $\mathrm{I} \mu \mathrm{g} . / \mathrm{ml}$. The threshold concentration of this insecticide, therefore, was below I $\mu \mathrm{g}$. $/ \mathrm{ml}$. Phorate inhibited the growth of this fungus at $2 \mu \mathrm{g} . / \mathrm{ml}$.

However, the threshold concentration as defined above (highest insecticide concentration at which no inhibition of fungal growth occurred) is not synonymous with the 'no effect' level. This is particularly shown with Aspergillus fumigatus in the presence of phorate (Fig. I $a$ ). The threshold concentration of this insecticide was $10 \mu \mathrm{g}$. $/ \mathrm{ml}$. However, a significant ( $\mathrm{I} \%$ level) growth stimulation was observed with phorate at I and $2 \mu \mathrm{g} . / \mathrm{ml}$., resulting in a 57 and $54 \%$ weight increase of the respective mycelia.

Experiment 3. Effects of insecticides on fungi grown on media lacking glucose or inorganic phosphate. Since most of the insecticides had some fungicidal effects, it was not surprising that none of the 17 fungi was able to utilize any of the insecticides as a carbon or phosphorus source. In the absence of glucose, fungi were still able to grow slightly (Pl. I). With the exception of aldrin, the addition of insecticides to glucosedeficient media further inhibited the growth of the fungal colonies. Plate I, fig. I shows the effect of lindane on the growth of Penicillium lilacinum on complete media (CK) and glucose-deficient media ( $-\mathrm{C}$ ), while Pl. I, fig. 2 presents the effect of parathion on the growth of Fusarium oxysporum in both glucose-deficient media $(-\mathrm{C})$ and phosphate-deficient media (-P). As shown in these examples, the absence of glucose resulted in decreased fungal growth which was further inhibited by lindane or parathion. Omission of inorganic phosphate, however, resulted in a $90 \%$ inhibition of growth of $F$. oxysporum; the addition of parathion to the phosphate-deficient medium had no effect.

Since aldrin in nutrient-deficient media did not further inhibit fungal growth, it is possible that the concentration of this insecticide $(40 \mu \mathrm{g} . / \mathrm{ml}$.) was too low to serve as a nutrient source.

Table 2. Effect of additions to the basic culture medium ${ }^{a}$ on the growthinhibitory action of insecticides (at $20 \mu \mathrm{g} . / \mathrm{ml}$.) on Fusarium oxysporum

Insecticide treatment

\begin{tabular}{|c|c|c|c|c|c|c|}
\hline \multirow{2}{*}{$\begin{array}{c}\text { Additions } \\
\text { to } \\
{\text { basic } \text { medium }^{a}}^{\text {a }}\end{array}$} & \multirow[t]{2}{*}{ None } & \multicolumn{2}{|l|}{ Carbaryl } & \multirow[t]{2}{*}{ None } & \multicolumn{2}{|c|}{ Aldrin } \\
\hline & & Dry weight (mg.) & $\% \mathrm{CK}^{b}$ & & Dry weight (mg.) & $\% \mathrm{CK}$ \\
\hline None & $39 \cdot 8 \pm 4 \cdot 27^{c}$ & $22 \cdot 3 \pm \mathrm{I} \cdot 93$ & 56 & $27 \cdot 3 \pm 2 \cdot 19$ & $I 7 \cdot I \pm I \cdot 69$ & 63 \\
\hline $\begin{array}{l}\text { Vitamins }{ }^{d} \\
\text { Yeast extract }\end{array}$ & $\begin{array}{l}39.9 \pm 0.93 \\
75.8 \pm 3.60\end{array}$ & $\begin{array}{l}22 \cdot 0 \pm I \cdot 14 \\
74 \cdot 8 \pm 5 \cdot 05\end{array}$ & 55 & $\begin{array}{l}26.5 \pm 2.68 \\
90.5 \pm 2.64\end{array}$ & $\begin{array}{l}15 \cdot 1 \pm 2 \cdot 20 \\
76 \cdot 7 \pm 1 \cdot 62\end{array}$ & $\begin{array}{l}57 \\
85^{e}\end{array}$ \\
\hline $\begin{array}{l}\text { None } \\
\text { Asparagine }\end{array}$ & $\begin{array}{l}36 \cdot 3 \pm I \cdot 53 \\
68 \cdot 7 \pm 2 \cdot 03\end{array}$ & $\begin{array}{l}21 \cdot 5 \pm 3 \cdot 57 \\
63 \cdot 2 \pm 3 \cdot 10\end{array}$ & $\begin{array}{l}59 \\
93^{e}\end{array}$ & $\begin{array}{l}40 \cdot 3 \pm 2 \cdot 67 \\
73 \cdot 5 \pm 5 \cdot 22\end{array}$ & $\begin{array}{l}26 \cdot 3 \pm 1 \cdot 62 \\
59 \cdot 7 \pm 4 \cdot 90\end{array}$ & $\begin{array}{l}65 \\
8 \mathrm{I}^{e}\end{array}$ \\
\hline $\begin{array}{l}\text { None } \\
\left(\mathrm{NH}_{4}\right)_{2} \mathrm{SO}_{4} \\
\mathrm{NH}_{4} \mathrm{NO}_{3} \\
\mathrm{NH}_{4} \mathrm{SO}_{3} \mathrm{NH}_{2}\end{array}$ & $\begin{array}{l}43 \cdot 6 \pm 3 \cdot 25 \\
56 \cdot 4 \pm 4 \cdot 16 \\
68 \cdot 1 \pm 3 \cdot 28 \\
60 \cdot 0 \pm 2 \cdot 77\end{array}$ & $\begin{array}{l}28 \cdot 4 \pm 5 \cdot 00 \\
50 \cdot 9 \pm 3 \cdot 01 \\
67 \cdot 6 \pm 3 \cdot 82 \\
55 \cdot 3 \pm 3 \cdot 27\end{array}$ & $\begin{array}{l}65 \\
90^{f} \\
99^{e} \\
92^{f}\end{array}$ & $\begin{array}{l}45.4 \pm 4.20 \\
54.5 \pm 3.67 \\
63.7 \pm 1 \cdot 84 \\
58.7 \pm 2.45\end{array}$ & $\begin{array}{l}26 \cdot 9 \pm 1 \cdot 78 \\
39 \cdot 4 \pm 4 \cdot 65 \\
47 \cdot 6 \pm 0 \cdot 75 \\
41 \cdot 0 \pm 2 \cdot 13\end{array}$ & $\begin{array}{l}59 \\
72^{f} \\
75^{e} \\
70^{e}\end{array}$ \\
\hline
\end{tabular}

${ }^{a}$ Basic culture medium contains $\mathrm{NaNO}_{3}$ as the only nitrogen source; ${ }^{b} \% \mathrm{CK}=$ insecticide-treated as $\%$ of untreated (none); ${ }^{c}$ standard deviation; ${ }^{d}$ thiamine, riboflavin, pyridoxine, niacin, pantothenic acid, biotin, folic acid, vitamin $\mathrm{B}_{12}$, inositol, choline: ${ }^{e}$ significantly different at the $\mathrm{I} \%$ level (t-test) from medium not containing additives; ${ }^{f}$ significantly different at the $5 \%$ level (t-test) from medium not containing additives. 
Experiment 4. Counteraction of insecticidal effects. (a) With yeast extract. The addition of yeast extract to the culture media decreased or counteracted the growth inhibitory effects of the insecticides and increased fungal growth in general (Pl. 2). Threshold concentrations of the insecticides were usually higher when yeast extract was included in the media. These concentrations, as measured with Fusarium oxysporum, increased from below I to $2 \mu \mathrm{g}$. $/ \mathrm{ml}$. with lindane (Pl. 2, fig. 3), from 2 to $5 \mu \mathrm{g} . / \mathrm{ml}$. with parathion, and from I to Io $\mu \mathrm{g} . / \mathrm{ml}$. with phorate, and from 5 to $20 \mu \mathrm{g} . / \mathrm{ml}$. with carbaryl. The threshold concentration of aldrin was not affected, although the actual growth inhibition at higher concentrations was less pronounced with yeast extract than it was on media that did not contain it (Pl. 2, fig. 4).

$(b)$ and $(c)$ With vitamins and nitrogen nutrients. Table 2 summarizes the results obtained after Fusarium oxysporum had been grown on carbaryl or aldrin-treated media to which yeast extract, vitamins or different sources of nitrogen had been added. The insecticides by themselves inhibited fungal growth by 37 to $44 \%$. However, yeast extract completely suppressed the inhibition by carbaryl and that by aldrin to a large extent. Replacement of the yeast extract with the vitamin mixture had no effect, since fungal growth was still inhibited by 45 and $43 \%$. It appears, therefore, that the growth inhibitory effects of carbaryl and aldrin were not related to interference with the function of these vitamins in $F$. oxysporum.

Addition of asparagine, ammonium sulphate, ammonium nitrate or ammonium sulphamate to the insecticide-treated media had an effect similar to that observed with yeast extract. The nitrogenous compounds counteracted or neutralized the toxic effects of the insecticides on growth of Fusarium oxysporum. This was especially the case with carbaryl. The toxic effects of aldrin were also somewhat decreased through the presence of these compounds.

It thus appears that a reduced inorganic form of nitrogen, or an organic form, is a more favourable nitrogen source for Fusarium oxysporum than is nitrate nitrogen. Carbaryl and aldrin apparently inhibited the growth of $F$. oxysporum by interfering with the utilization of nitrate nitrogen. It also appears that there are other factors involved, since inhibition with aldrin was not completely overcome by the addition of these nitrogen sources. Carbaryl could have interfered with the absorption of nitrate or its subsequent metabolism in cells, while reduced or organic nitrogen compounds were not affected by this insecticide. Aldrin, on the other hand, could have interfered with the uptake or metabolism of both nitrate and reduced nitrogen, but to a greater degree with that of nitrate.

The data presented show that the five insecticides affect the growth of some soil microfungi in culture, and threshold studies show that the inhibitory effects occur at concentrations that might be encountered under field conditions. However, because of adsorption and metabolism phenomena in soils (Lichtenstein, 1966; Lichtenstein, Fuhremann \& Schulz, I968), these insecticides will have different effects in field soils.

Special thanks are expressed to Professor W. Whittingham, Department of Botany, University of Wisconsin, for supplying the various fungi and for his advice during the course of these investigations.

This paper is published with the approval of the Director of the Research Division, College of Agricultural and Life Sciences. The work was supported in part by a grant from the U.S. Public Health Service (FD-00258, formerly CC-297). This is a contri- 
bution from the Wisconsin Agricultural Experiment Station as a collaborator under North Central Regional Co-operative Research Project 85 entitled 'Reduction of hazards associated with the presence of residues of insecticidal chemicals in the environment'.

\section{REFERENCES}

Ainsworth, G. C. (1960). Dictionary of the Fungi, 5th edn. Commonwealth Mycological Institute of Great Britain.

Engst, R. \& KuJAwa, M. (1968). Enzymatischer Abbau des DDT durch Schimmelpilze. Die Nahrung I2, 783.

Kearney, P. C., Kaufman, D. D., von Endt, D. W. \& Guardia, F. S. (I969). TCA metabolism by soil micro-organisms. Journal of Agricultural and Food Chemistry 17, 58I.

Ko, W. H. \& Lockwood, J. L. (1968). Conversion of DDT to DDD in soil and the effect of these compounds on soil micro-organisms. Canadian Journal of Microbiology 14, 1069.

Lichtenstern, E. P. (I966). Persistence and degradation of pesticides in the environment. Scientific aspects of pest control. National Academy of Sciences of the United States of America Publ. no. I4O2, 221 .

Lichtenstein, E. P., Funtremann, T. W. \& Schulz, K. R. (1968). Use of carbon to reduce the uptake of insecticidal soil residues by crop plants. Journal of Agricultural and Food Chemistry 16, 348.

Matsumura, F., Boush, G. M. \& TaI, A. (1968). Breakdown of dieldrin in the soil by micro-organisms. Nature, London 219, 965.

ORPURT, P. A. \& CURTIS, J. T. (1957). Soil microfungi in relation to the prairie continuum in Wisconsin. Ecology 38, 628.

Richardson, L. T. \& MilleR, D. M. (1960). Fungitoxicity of chlorinated hydrocarbon insecticides in relation to water solubility and vapour pressure. Canadian Journal of Botany 38, I63.

Sethunathan, N. \& MacRae, I. C. (1969). Persistence and biodegradation of Diazinon in submerged soils. Journal of Agricultural and Food Chemistry 17, $22 \mathrm{I}$.

\section{EXPLANATION OF PLATES}

$\mathrm{CK}=$ Effects of insecticide in complete culture media; $-\mathrm{C}=$ effects of insecticide in glucosedeficient media; $-\mathrm{P}=$ effects of insecticide in phosphate-deficient media. Media to the right are insecticide-treated.

Plate I

Effect of insecticides on growth of fungi.

Fig. I. Penicillium lilacinum on lindane-treated media.

Fig. 2. Fusarium oxysporum on parathion-treated media.

\section{Plate 2}

Effects of insecticides and yeast extract on Fusarium oxysporum grown on culture media with ( $\mathrm{Y}$ ) or without $(-Y)$ yeast extract.

Fig. 3. Media treated with lindane.

Fig. 4. Media treated with aldrin. 

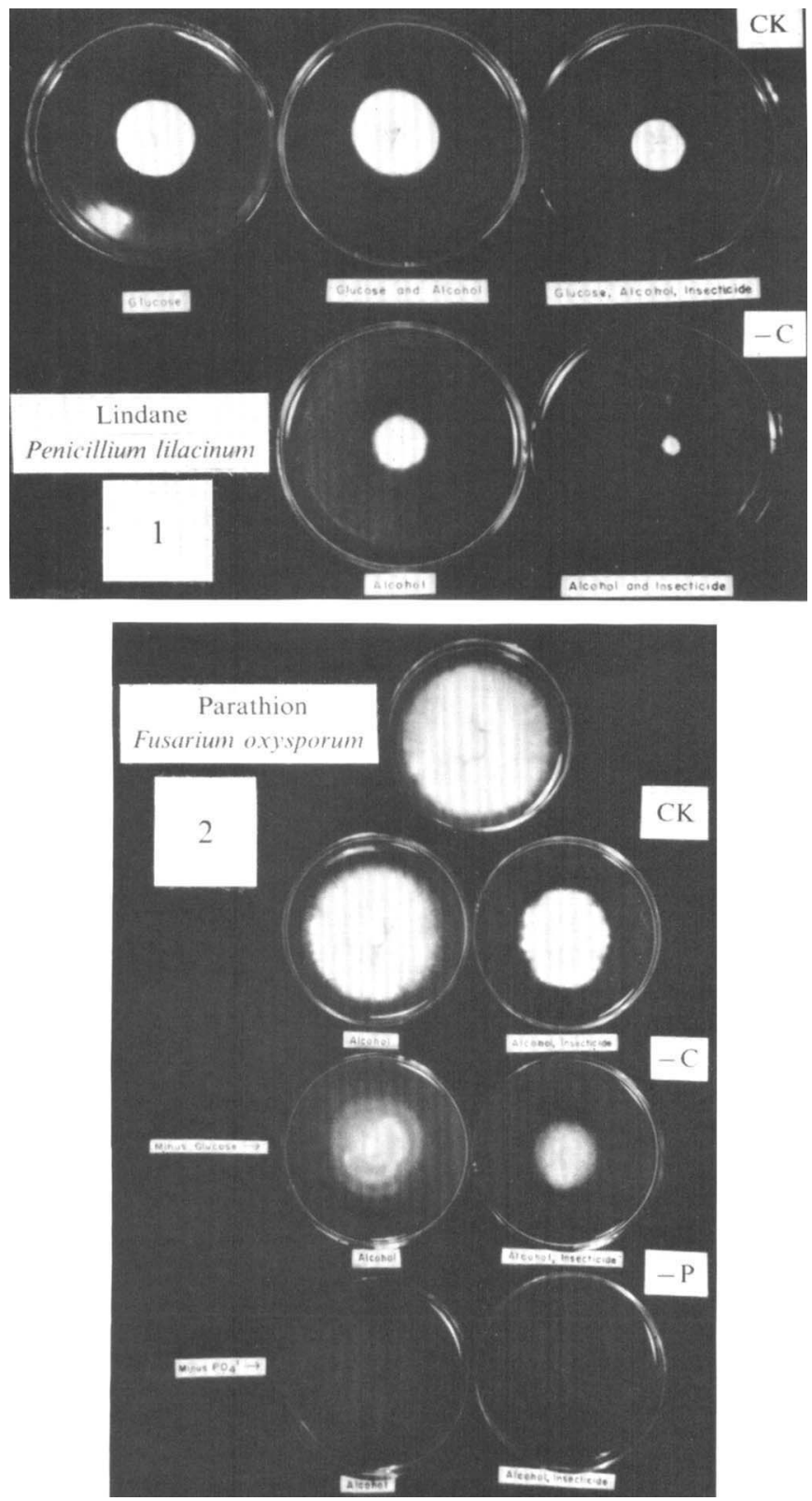

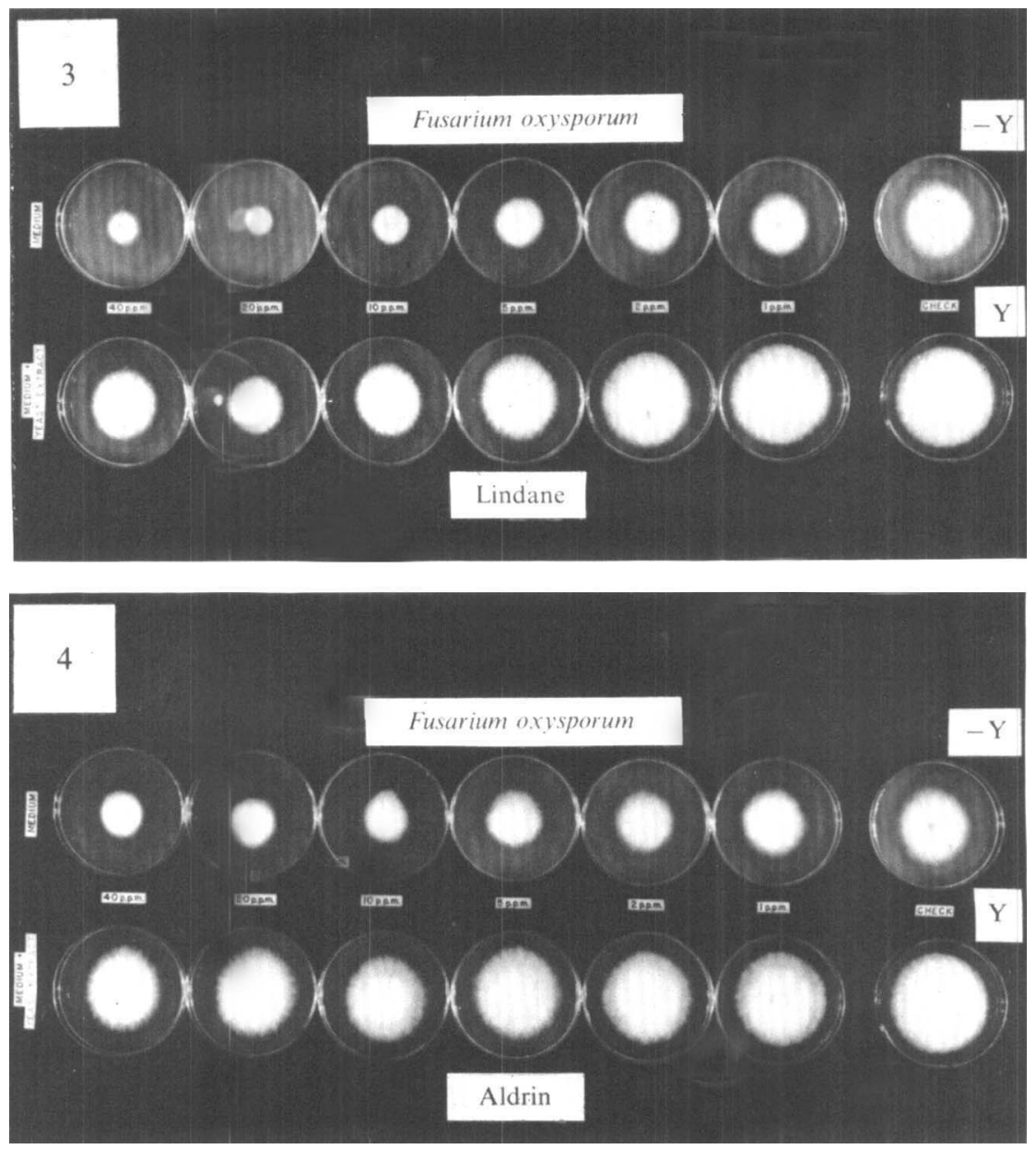

G. T. COWLEY AND E. P. LICHTENSTEIN 